\title{
Male BRCA mutation carriers: clinical characteristics and cancer spectrum
}

\author{
Mohammed Ibrahim ${ }^{1,2^{*}}$ (D) Siddhartha Yadav ${ }^{3}$, Foluso Ogunleye ${ }^{1,2}$ and Dana Zakalik ${ }^{2,4}$
}

\begin{abstract}
Background: Mutations in BRCA1 and BRCA2 (BRCA1/2) genes are associated with an increased risk of breast and ovarian cancers in women. The cancer characteristics of men with BRCA1/2 mutations are less well studied. This study describes the unique cancer characteristics of male BRCA1/2 mutation carriers at our institution.

Methods: We performed a retrospective chart review on male patients who were seen between January 2004 and December 2014 and tested positive for a BRCA1/2 mutation. We evaluated clinical characteristics, pathology findings, treatment selection and survival.

Results: A total of 102 male patients were identified who tested positive for a BRCA1/2 deleterious mutation. Of these 102 patients, 33 (32\%) had a diagnosis of cancer. Of these 33 patients with cancer, the majority (20 patients) were found to carry a BRCA2 mutation. Median age of cancer diagnosis was 65 years (Range: 35-75 years). Of the 33 patients diagnosed with cancer, 8 had two or more cancers, including 1 patient who had 4 cancers. Prostate cancer was the most commonly diagnosed cancer, seen in 13 patients, 11 of whom were BRCA2 positive. These cancers tended to have higher Gleason scores and elevated PSA levels. The majority of these prostate cancer patients were alive and disease free at a median follow-up of 7.4 years. Male breast cancer was the second most common cancer seen in 9 patients, all of whom were BRCA2 positive. The majority of these cancers were high grade, hormone receptor positive and associated with lymph node metastases. There were no breast cancer related deaths. Other cancers included bladder cancer, pancreatic cancer, melanoma and other skin cancers.

Conclusions: This study describes the cancer characteristics and outcomes of male BRCA1/2 mutation carriers. A third of male BRCA1/2 mutation carriers had a diagnosis of cancer. A significant number of patients (mostly BRCA2 mutation positive) developed multiple cancers, which may have important implications for cancer screening and prevention. Despite having high grade histology and advanced stage at diagnosis, male BRCA1/2 mutation carriers with breast and prostate cancer demonstrated a favorable 5-year survival.
\end{abstract}

Keywords: BRCA mutations, Male breast cancer, Prostate cancer, Melanoma, Survival

\section{Background}

BRCA1 and BRCA2 (BRCA1/2 hereafter) are tumor suppressor genes involved in DNA repair and maintenance of genomic stability. Mutations in BRCA1/2 genes account for 20 to $25 \%$ of all hereditary breast cancers [1] and about $5-10 \%$ of all breast cancers [2]. Pathogenic BRCA1/2 mutations are highly penetrant mutations that are inherited in an autosomal dominant fashion and result in a significantly

\footnotetext{
* Correspondence: mohammed.ibrahim@beaumont.org

'Department of Hematology/Oncology, Beaumont Health, 3577 W 13 Mile Rd., Ste. 202a, Royal Oak, Ml 48073, USA

${ }^{2}$ Oakland University William Beaumont School of Medicine, 2200 N Squirrel

Rd, Rochester, MI 48309, USA

Full list of author information is available at the end of the article
}

increased risk of breast, ovarian, prostate, melanoma, pancreatic and other cancers [3-7]. While there has been extensive research on the risk of cancer in women with $B R C A 1 / 2$ mutations, the cancer characteristics of men with $B R C A 1 / 2$ mutations have not been well studied.

Men with $B R C A 1 / 2$ mutations are at increased risk for breast, prostate, pancreatic and other cancers $[3-5,8]$. Male breast cancer is rare in the general population with a lifetime risk of $0.1 \%$, although the risk is significantly increased to $7-8 \%$ with $B R C A 2$ mutation and $1 \%$ with a $B R C A 1$ mutation [3, 4]. Up to $14 \%$ of men diagnosed with breast cancer are found to harbor a BRCA2 mutation [8]. Two prior studies have reported worse prognosis in male 
breast cancer patients with a deleterious $B R C A 1 / 2$ mutation compared to those without a mutation $[9,10]$. However, both studies were limited by their small sample size. There is limited knowledge about the clinical characteristics of male $B R C A 1 / 2$ mutation carriers.

The risk of prostate cancer is up to fivefold higher in $B R C A 2$ mutation carriers [5, 6]. BRCA1/2 mutation associated prostate cancers have been reported to be more aggressive and associated with a worse survival compared to $B R C A$ wild type cancers [11-14]. Castro et al. reported on 79 patients with prostate cancer who were positive for a $B R C A 1 / 2$ mutation and found that these patients frequently presented with higher Gleason scores $(\geq 8)$, higher $\mathrm{T}$ stage (T3 or T4), nodal involvement and metastases at diagnosis [12].

$B R C A 1 / 2$ associated breast cancers have been known to respond better to platinum based chemotherapy [15]. Knowledge of $B R C A 1 / 2$ mutation status can have therapeutic implications which can impact survival. PARP (poly adenosine diphosphate-ribose polymerase) inhibitors are being used increasingly in advanced breast and ovarian cancer in women [1619]. These findings are expanding to treatment of male BRCA associated cancers. A recent study demonstrated a significant response to a PARP inhibitor, Olaparib, in patients with advanced castrate resistant prostate cancer with $B R C A$ mutations [20]. Whether these therapeutic agents and the knowledge of $B R C A$ mutation status translate to better outcomes in men is not yet known.

In summary, while little is known about the clinical characteristics and outcomes of male BRCA mutation carriers, there is a growing imperative to expand our understanding of this unique population. We present an analysis of male $B R C A$ mutation carriers from our cancer genetics clinic database and describe their unique features and outcomes.

\section{Methods}

After Institutional Review Board approval, we performed a retrospective chart review on male $B R C A 1 / 2$ mutation carriers identified at the Nancy and James Grosfeld Cancer Genetics Center from January 2004 to December 2014. Patients with a pathogenic or likely pathogenic $B R C A 1 / 2$ mutation were included in the study, while those with variants of undetermined significance were excluded. We used CLIA certified commercial laboratories such as Ambry, Myriad and Invitae, (which are widely used in academic centers), to obtain the information about pathogenicity, which was also individually verified for concordance using databases such as ClinVar. We looked at the demographic information including their age, race, ethnicity and reason for testing. We then studied the subset of male $B R C A 1 / 2$ mutation carriers who were diagnosed with cancer, either prior to or after the testing was performed. We evaluated the type of cancer, clinical staging, histo-pathologic information, treatment and survival. We used SPSS version- 21 statistical software for data analysis.

\section{Results \\ Demographics}

A total of 102 male patients were identified who tested positive for a $B R C A 1 / 2$ deleterious mutation. Fifty-three (52\%) of these 102 patients were positive for a $B R C A 1$ mutation and $49(48 \%)$ were positive for a $B R C A 2$ mutation. The median age at the time of testing was 55 years (Range: 19-85 years).

The race and ethnicities of these 102 individuals are included in Table 1 . The majority were Caucasian, of whom a quarter were Ashkenazi Jewish.

\section{Genetic testing}

The most common reasons for testing were a family history of breast or ovarian cancer or a known $B R C A 1 / 2$ mutation in the family, which was present in 98 of the 102 patients. A new diagnosis of male breast cancer prompted $B R C A 1 / 2$ testing in the 4 individuals without a family history of breast and ovarian cancer.

Of the non-Ashkenazi Jewish population, 66 patients (86\%) underwent single site testing, 9 patients $(12 \%)$ had full sequence testing and $2(2 \%)$ had multi-gene panel testing. Of the 25 Ashkenazi Jewish patients who tested positive for a $B R C A 1 / 2$ mutation, the majority were identified using the 3 site Ashkenazi Jewish panel, while an additional 3 patients were identified to carry an elsewhere mutation, after being tested negative for the 3 site Ashkenazi Jewish panel.

\section{Cancer characteristics}

Of the 102 patients who tested positive for a $B R C A 1 / 2$ mutation, 33 (32\%) had a diagnosis of cancer (Fig. 1). Of these 33 patients with cancer, the majority (20 patients) were found to carry a $B R C A 2$ mutation. Median age of diagnosis with cancer was 65 years (Range: $35-75$ years). A total of 44 cancers were diagnosed in these 33 patients.

Of the 33 patients diagnosed with cancer, the majority (25 patients) had 1 cancer. A quarter of patients (8 patients) had more than 1 cancer. Of these 8 patients, 6 had 2 cancers, 1 patient had 3 cancers (breast, prostate and lymphoma) and 1 patient had 4 different cancers (breast cancer, DCIS, prostate and small cell neuroendocrine cancer) (Figs. 1 and 2). Of the 8 patients diagnosed with multiple cancers, the majority (7 patients) had a $B R C A 2$ mutation. A third (7 patients) of the $20 B R C A 2$ mutated patients with cancer had multiple cancers.

Prostate cancer was the most commonly diagnosed cancer, followed by male breast cancer, bladder cancer, 
Table 1 Ethnicities of male BRCA mutation carriers

\begin{tabular}{|c|c|c|}
\hline Race/ethnicity & Total BRCA mutation carriers (\%) & Diagnosed with cancer (\%) \\
\hline Caucasian & $97(95)$ & $32(97)$ \\
\hline Ashkenazi Jewish & $25(25)$ & $10(30)$ \\
\hline Iraqi & $3(3)$ & $3(9)$ \\
\hline Greek & $1(1)$ & $1(3)$ \\
\hline Lebanese & $1(1)$ & $1(3)$ \\
\hline Hispanic & $1(1)$ & $1(3)$ \\
\hline African American & $2(2)$ & $1(3)$ \\
\hline Asian & $3(3)$ & - \\
\hline Indian & $1(1)$ & - \\
\hline Filipino & $2(2)$ & - \\
\hline Total & 102 & 33 \\
\hline
\end{tabular}

melanoma and other skin cancers (Fig. 1, Tables 2 and 3). Ten patients had a diagnosis of non-melanoma skin cancer. Other cancers diagnosed in this group included pancreatic cancer, small cell neuroendocrine cancer, squamous cell lung cancer and lymphomas (Table 4 and Fig. 2).

\section{Prostate cancer}

Thirteen patients had a diagnosis of prostate cancer (Table 2). The majority (11) of these patients had a $B R C A 2$ mutation. Median age at diagnosis with prostate cancer was 68 years (Range: 51 to 80 years). Of the 4 patients for whom PSA (prostate specific antigen) data was available, the median PSA level at diagnosis was $14.37 \mathrm{ng} / \mathrm{ml}$ (Range: 2.7 to $1497 \mathrm{ng} / \mathrm{ml}$ ). Of the $8 \mathrm{pa}-$ tients for whom staging information was available, 3 had stage II disease, 2 patients had stage I disease, 2 had stage IV disease and 1 patient had stage III disease. Of the 9 patients for whom Gleason score was available, the median Gleason score was 7 (Range: 6-9). Most patients were treated with either radical prostatectomy (6 patients) or primary radiation therapy (5 patients). The remaining 2 patients had stage IV disease and were treated with palliative chemotherapy (Docetaxel), androgen deprivation therapy (ADT) and palliative radiation therapy to the spine.

Survival data was available for 12 patients. Two patients died during a median follow-up of 7.4 years (Range: 0.3 - 15.6 years). One patient died 4 months after diagnosis from stage IV disease with extensive bone, liver and lung metastases and another patient died at 2.2 years, also from extensive bone and liver metastases. The 1- and 5-year survival was $91.6 \%$ and $83.3 \%$

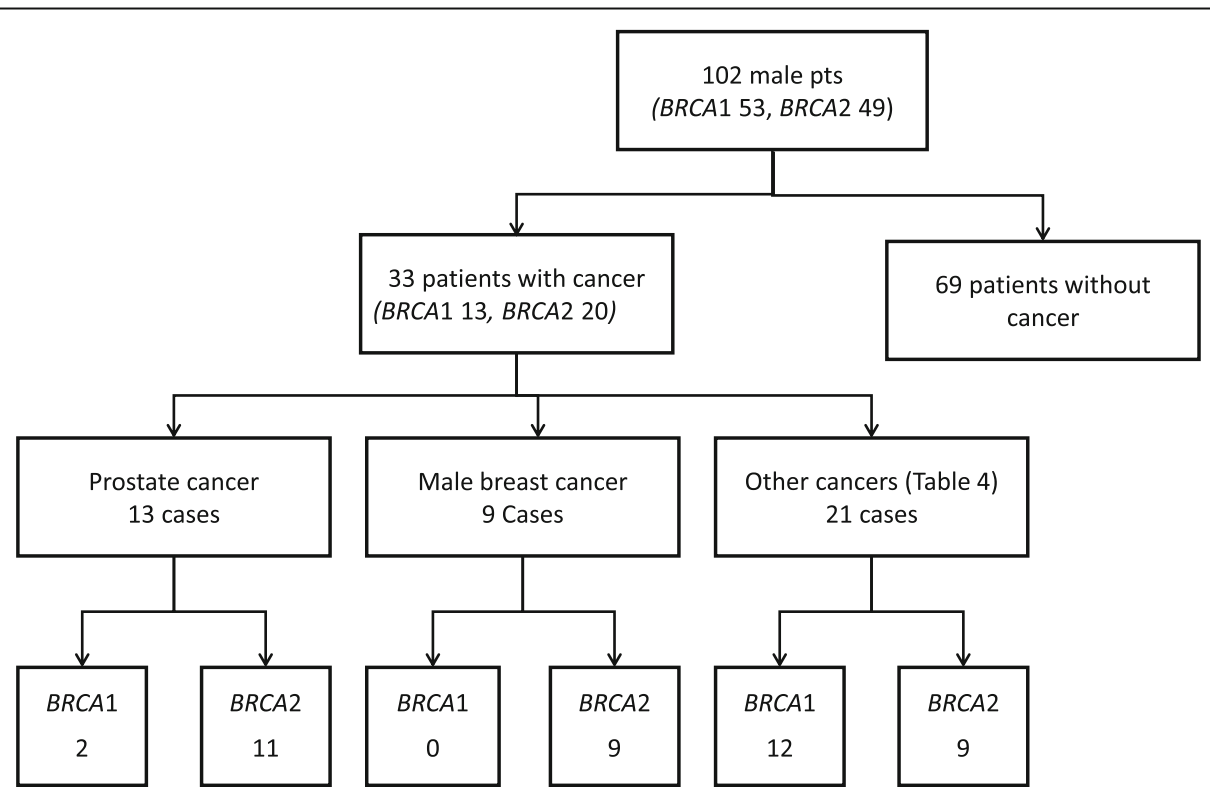

Fig. $1 B R C A$ mutation carriers and diagnosis of cancer 


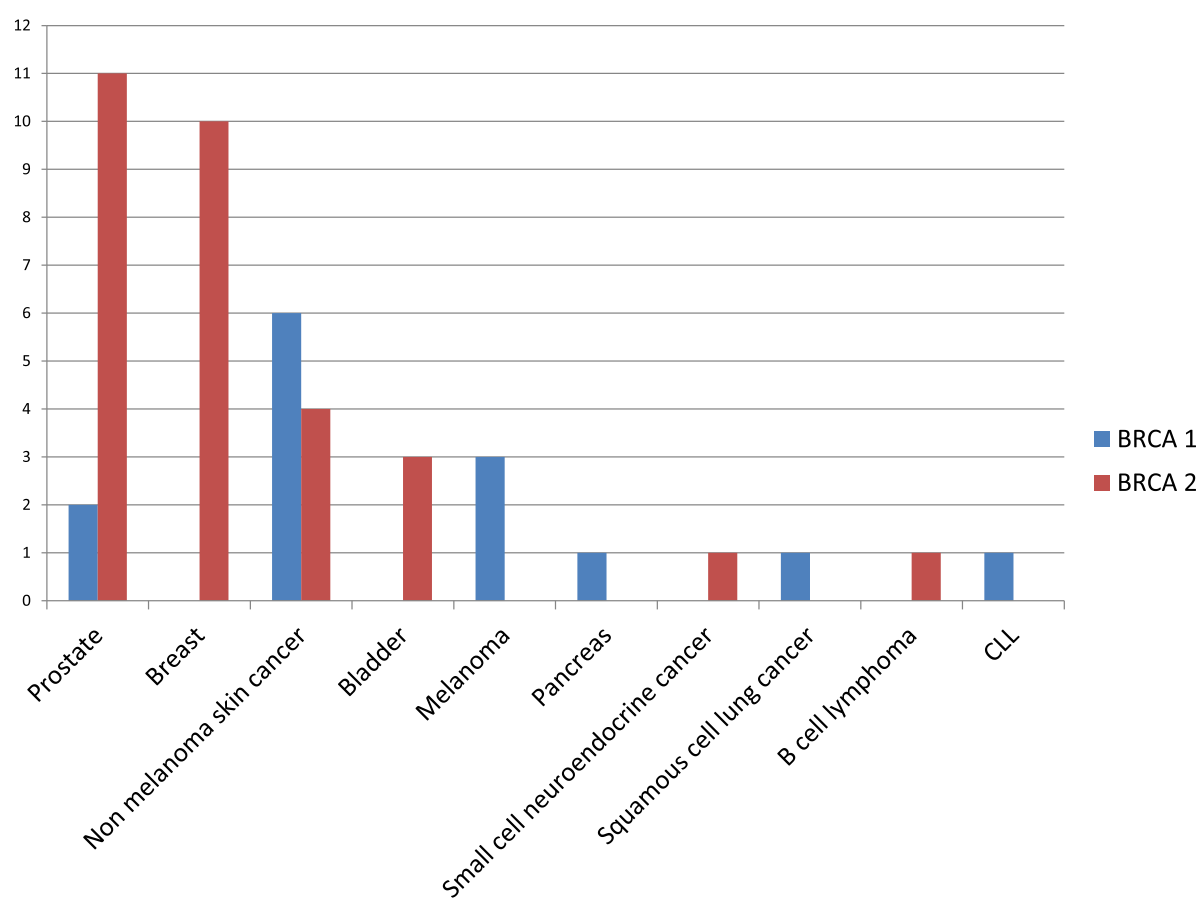

Fig. 2 Types of cancers diagnosed in 33 male BRCA mutation carriers

respectively (Fig. 3). The 5- year prostate cancer specific survival was $83.3 \%$.

\section{Male breast cancer}

Nine patients had a diagnosis of male breast cancer (Table 3). All of these 9 patients had a BRCA2 mutation. Median age at breast cancer diagnosis was 67 years (Range: $52-75$ years). All of the 8 patients for whom pathology was available, had infiltrating ductal carcinomas and one of these also had a contralateral DCIS (ductal carcinoma in situ). All of these 8 patients had hormone receptor ER (estrogen receptor) positive cancers and 6 had high grade histology. Of the 7 patients for whom lymph node status was available, 6 patients had lymph node metastases at diagnosis. Staging information was available for 7 patients. Four of these 7 patients had stage II disease, 1 patient had stage I disease and 2 patients had stage III disease. Four out of the 7 patients for whom human epidermal growth factor receptor (HER-2) status was available, were HER - 2 positive. Eight patients had available surgical treatment data and all eight patients underwent a mastectomy. Five of the 9 breast cancer patients received adjuvant radiation therapy. Seven patients received chemotherapy, as depicted in Table 3. All but 1 patient took Tamoxifen. Two patients died during a median follow-up of 5.6 years. One patient died 15.8 years after diagnosis, from small cell neuroendocrine cancer and another patient died 2.3 years after diagnosis from widely metastatic prostate cancer. There were no breast cancer associated deaths. The 1- and 5- year survival was 100\% and $83.3 \%$ respectively (Fig. 4 ). The 5 - year breast cancer specific survival was $100 \%$.

\section{Other cancers}

Three patients were diagnosed with malignant melanoma. Ten patients were diagnosed with non-melanoma skin cancers (Table 4). One of the 3 patients with melanoma had an aggressive anal melanoma, which presented with stage IV disease. This patient was treated with multiple lines of chemotherapy including Cisplatin as well as a PARP inhibitor. He initially had a good response to the PARP inhibitor, but eventually succumbed to the disease. Three patients were diagnosed with bladder carcinoma. One patient was diagnosed with metastatic pancreaticobiliary adenocarcinoma. One patient had small cell neuroendocrine carcinoma of liver and was treated with Carboplatin and Etoposide chemotherapy. One patient was diagnosed with squamous cell lung carcinoma and elected for hospice care in view of advanced age and multiple co-morbidities.

\section{Discussion}

This study represents one of the largest retrospective studies of cancers in male $B R C A 1 / 2$ mutation carriers, consisting of 102 male patients who were identified in a clinical cohort. Given the paucity of recent literature on cancer characteristics in male $B R C A$ mutation carriers, 
Table 2 Cancer characteristics of male BRCA mutation carriers with prostate cancer

\begin{tabular}{|c|c|c|c|c|c|c|c|c|c|c|c|c|}
\hline $\begin{array}{l}\text { Patient } \\
\text { ID }\end{array}$ & $\begin{array}{l}\text { BRCA } \\
\text { Gene }\end{array}$ & Mutation & $\begin{array}{l}\text { Age at } \\
\text { diagnosis }\end{array}$ & PSA & Stage & TNM & Gleason & Surgery & RT & ADT & Status & $\begin{array}{l}F / U \\
(Y r s)\end{array}$ \\
\hline 15 & 1 & c.181 T> G & 51 & N.A & $\|$ & $\mathrm{T} 2 \mathrm{Nx}$ & 7 & yes & N.A & N.A & $\begin{array}{l}\text { Alive, } \\
\text { NED }\end{array}$ & 5.4 \\
\hline 10 & 1 & c. $4096+1$ G > A & 80 & N.A & NA & N.A & N.A & NA & yes & N.A & $\begin{array}{l}\text { Alive, } \\
\text { NED }\end{array}$ & 13 \\
\hline 4 & 2 & c.100 G > T & 72 & N.A & NA & N.A & 6 & Yes, RP & NA & NA & $\begin{array}{l}\text { Alive, } \\
\text { NED }\end{array}$ & 10.1 \\
\hline 3 & 2 & c.1813dupA & 58 & 7.9 & । & T1 No & 6 & NA & yes & N.A & $\begin{array}{l}\text { Alive, } \\
\text { NED }\end{array}$ & 15.6 \\
\hline 5 & 2 & c.2808del4 & 66 & N.A & N.A & N.A & N.A & N.A & yes & N.A & $\begin{array}{l}\text { Alive, } \\
\text { NED }\end{array}$ & 5 \\
\hline 1 & 2 & c.2808del4 & 67 & N.A & early & N.A & 6 & no & yes, EBRT & Leuprolide-3 years & $\begin{array}{l}\text { Alive, } \\
\text { NED }\end{array}$ & 7.1 \\
\hline 12 & 2 & c.5576del4 & 75 & 20.84 & IV & N.A & 9 & no & $\begin{array}{l}\text { Palliative RT } \\
\text { to spine }\end{array}$ & Leuprolide & Expired & 0.3 \\
\hline 16 & 2 & c.5576del4 & 70 & N.A & III & T3 NO & 8 & yes, RP & N.A & Leuprolide & $\begin{array}{l}\text { Alive, } \\
\text { NED }\end{array}$ & 10 \\
\hline 14 & 2 & c.5946delT & 64 & 2.7 & N.A & N.A & N.A & yes, RP & N.A & N.A & N.A & N.A \\
\hline 7 & 2 & c.5946delT & 74 & N.A & N.A & N.A & 7 & yes, RP & N.A & Leuprolide & $\begin{array}{l}\text { Alive, } \\
\text { NED }\end{array}$ & 8.1 \\
\hline 13 & 2 & c.7558 C > T & 67 & N.A & $\|$ & $\mathrm{T} 2, \mathrm{NO}$ & 7 & no & brachytherapy & N.A & $\begin{array}{l}\text { Alive, } \\
\text { NED }\end{array}$ & 7.6 \\
\hline 11 & 2 & $c .9317 G>A$ & 65 & N.A & ॥ & T2 No & 7 & Yes,RP & N.A & N.A & $\begin{array}{l}\text { Alive, } \\
\text { NED }\end{array}$ & 5.2 \\
\hline 6 & 2 & c.6333_6337delGAGAA & 68 & 1497 & IV & N.A & N.A & N.A & N.A & $\begin{array}{l}\text { Bicalutamide, } \\
\text { Leuprolide, } \\
\text { Abiraterone }\end{array}$ & Expired & 2.2 \\
\hline
\end{tabular}

$R T$ radiation therapy, RP Radical prostatectomy, $A D T$ androgen deprivation therapy, NED no evidence of disease, NA not available, PSA value in $\mathrm{ng} / \mathrm{ml}$, cutoff value $4 \mathrm{ng} / \mathrm{ml}$

Table 3 Cancer characteristics of male BRCA mutation carriers with breast cancer

\begin{tabular}{|c|c|c|c|c|c|c|c|c|c|c|c|c|c|c|c|c|}
\hline ID & $\begin{array}{l}\text { BRCA } \\
\text { Gene }\end{array}$ & Mutation & $\begin{array}{l}\text { Age at } \\
\text { diagnosis }\end{array}$ & $\begin{array}{l}\text { Size } \\
(\mathrm{cm})\end{array}$ & LN & Stage & $\begin{array}{l}\text { TNM } \\
\text { stage }\end{array}$ & Grade & $\begin{array}{l}\text { ER } \\
\%\end{array}$ & $\begin{array}{l}\text { PR } \\
\%\end{array}$ & HER-2 & Surgery & Chemo & RT & Status & $\begin{array}{l}F / U \\
\text { (yrs) }\end{array}$ \\
\hline 4 & 2 & c.100G > T & 75 & 1.4 & neg & I & T1N0M0 & 2 & 92 & 18 & pos & M & $\begin{array}{l}\text { Yes, } \\
\text { Trastuzumab }\end{array}$ & no & $\begin{array}{l}\text { Alive, } \\
\text { NED }\end{array}$ & 5.7 \\
\hline 8 & 2 & c.736del20 & 52 & N.A & N.A & N.A & N.A & 3 & 97 & 87 & $\begin{array}{l}\text { Border- } \\
\text { line }\end{array}$ & M & yes, TCH & yes & Alive & 5.6 \\
\hline 3 & 2 & c.1813dupA & 58 & 1.3 & pos & ॥ & T2N1M0 & 3 & 59 & 50 & neg & M & yes, AC & yes & Expired & 15.8 \\
\hline 5 & 2 & c.2808del4 & 67 & 1.7 & pos & III & T1N3M0 & 3 & 100 & 89 & pos & M & yes, ACTH & yes & $\begin{array}{l}\text { Alive, } \\
\text { NED }\end{array}$ & 3.4 \\
\hline 1 & 2 & c.2808del4 & 68 & 1.6 & pos & $\|$ & T2N1M0 & 3 & 90 & 40 & neg & M & Yes, AC-T & yes & $\begin{array}{l}\text { Alive, } \\
\text { NED }\end{array}$ & 7.0 \\
\hline 7 & 2 & c.5946del T & 62 & N.A & pos & $\|$ & N.A & 3 & 90 & N.A & N.A & M & Yes,CMF & yes & $\begin{array}{l}\text { Alive, } \\
\text { NED }\end{array}$ & 21.0 \\
\hline 9 & 2 & c.5946delT & 67 & N.A & N.A & N.A & N.A & N.A & N.A & N.A & N.A & N.A & N.A & N.A & N.A & N.A \\
\hline 2 & 2 & c.6676_6677delGA & 62 & 2.5 & pos & $\|$ & T2N1M0 & 2 & 100 & 37 & pos & M & yes, TCHP & no & $\begin{array}{l}\text { Alive, } \\
\text { NED }\end{array}$ & 1.8 \\
\hline 6 & 2 & c.6333_6337delGAGAA & 68 & 6.0 & pos & III & T4N2M0 & 3 & 97 & 29 & neg & M & N.A & N.A & Expired & 2.3 \\
\hline
\end{tabular}


Table 4 Other cancers diagnosed in male BRCA mutation carriers

\begin{tabular}{|c|c|c|c|c|c|c|c|c|c|c|}
\hline Cancer & Patient ID & BRCA gene & Mutation & Age at $d x$ & Stage & Surgery & Chemotherapy & RT & Status & $F / U(Y r s)$ \\
\hline \multirow{3}{*}{$\begin{array}{l}\text { Melanoma } \\
N=3\end{array}$} & 19 & 1 & c.66dupA & 36 & Early & yes & no & no & N.A & N.A \\
\hline & 17 & 1 & c.68delAG & 62 & IV & N.A & $\begin{array}{l}\text { Yes (Cisplatin, PARP } \\
\text { inhibitor clinical trial) }\end{array}$ & yes & expired & 0.9 \\
\hline & 18 & 1 & $\begin{array}{l}\text { del exons 1- } \\
7\end{array}$ & 67 & early & yes & no & no & N.A & N.A \\
\hline \multirow{3}{*}{$\begin{array}{l}\text { Bladder } \\
N=3\end{array}$} & 20 & 2 & c.5576del4 & 47 & early & Yes (TURBT) & no & no & N.A & N.A \\
\hline & 22 & 2 & c. $5782 \mathrm{G}>\mathrm{T}$ & 70 & IV & $\begin{array}{l}\text { Yes (nephro- } \\
\text { ureterectomy) }\end{array}$ & $\begin{array}{l}\text { Yes (Carboplatin, } \\
\text { Paclitaxel, Pemetrexed }\end{array}$ & yes & expired & 2.4 \\
\hline & 21 & 2 & c.5946delT & 59 & early & Yes (TURBT) & no & no & $\begin{array}{l}\text { Alive, } \\
\text { NED }\end{array}$ & 4.7 \\
\hline $\begin{array}{l}\text { Squamous cell } \\
\text { lung cancer }\end{array}$ & 23 & 1 & C. $5123 \mathrm{C}>\mathrm{A}$ & 87 & III & No (declined) & No (declined) & $\begin{array}{l}\text { No } \\
\text { (declined) }\end{array}$ & expired & 1.1 \\
\hline $\begin{array}{l}\text { Neuroendocrine } \\
\text { carcinoma }\end{array}$ & 3 & 2 & c.1813dupA & 73 & IV & no & $\begin{array}{l}\text { Yes (Carboplatin, } \\
\text { Etoposide) }\end{array}$ & no & expired & 1.4 \\
\hline Pancreas & 24 & 1 & c. 2475 delC & 60 & IV & N.A & $\begin{array}{l}\text { Yes (Gemcitabine, } \\
\text { Carboplatin, FOLFOX) }\end{array}$ & no & Expired & 4.2 \\
\hline Lymphoma & 1 & 2 & c.2808del4 & 68 & N.A & N.A & N.A & N.A & N.A & N.A \\
\hline CLL & 25 & 1 & c.68delAG & 50 & N.A & N.A & N.A & N.A & alive & 1.1 \\
\hline \multirow{10}{*}{$\begin{array}{l}\text { Other Cancers } \\
N=10\end{array}$} & 28 & 1 & c.68delAG & 65 & early & yes & N.A & N.A & alive & N.A \\
\hline & 26 & 1 & c. 2475 delC & 55 & early & yes & N.A & N.A & N.A & N.A \\
\hline & 30 & 1 & c. $4524 \mathrm{G}>\mathrm{A}$ & 55 & early & yes & N.A & N.A & N.A & N.A \\
\hline & 23 & 1 & C. $5123 \mathrm{C}>\mathrm{A}$ & 74 & early & yes & N.A & N.A & N.A & N.A \\
\hline & 29 & 1 & c.5266dupC & 37 & early & yes & N.A & $\mathrm{N}, \mathrm{A}$ & N.A & N.A \\
\hline & 31 & 1 & $\begin{array}{l}\text { del exons } \\
13-15\end{array}$ & NA & early & yes & N.A & N.A & N.A & N.A \\
\hline & 22 & 2 & $c .5782 \mathrm{G}>\mathrm{T}$ & 58 & early & yes & N.A & N.A & N.A & N.A \\
\hline & 33 & 2 & c.9196C > T & 60 & early & yes & N.A & N.A & N.A & N.A \\
\hline & 27 & 2 & $c .9382 C>T$ & 35 & early & yes & N.A & N.A & N.A & N.A \\
\hline & 32 & 2 & 1881 delC & 70 & early & yes & N.A & N.A & N.A & N.A \\
\hline
\end{tabular}

$R T$ radiation therapy, F/U follow-up, TURBT transurethral resection of bladder tumor, FOLFOX Infusional fluorouracil, leukovorin and oxaliplatin, N.A not available

this study will help enhance our understanding of the cancer characteristics in this unique population. The most common reason for testing among our male population was a family history of breast and ovarian cancer, which was present in 98 (96\%) of the 102 patients. Only 4 of the 102 patients were tested after their own cancer diagnosis. It is important to be aware that male breast cancer may be the first manifestation of a BRCA mutation in a family, reinforcing the NCCN recommendation that every male breast cancer patient should be tested for a $B R C A$ mutation [21].

Despite having a family history of breast and ovarian cancer, the majority of males in our study underwent single site testing, suggesting that testing typically occurred after another family member was identified with a mutation. Other studies have also shown that males are less likely to test for $B R C A$ mutations [22-24]. Despite autosomal inheritance, males tend to be less likely to be the first in the family to test. One possible reason for this observation is physician bias regarding $B R C A$ impacting women given the well-known association of $B R C A$ mutation with female cancers. Other reasons include lack of awareness that breast cancer can affect men or that breast cancer genes can be transmitted by males and also less willingness of males with regard to genetic testing [22-24].

Almost a third of male patients with a BRCA mutation had a diagnosis of cancer, but only 4 patients were tested because of the cancer diagnosis. The median age of diagnosis of any cancer was 65 years. There was no identifiable pattern of mutations with respect to the region of the gene or the type of mutation, among the people unaffected by cancer, compared to those who developed a cancer. Of the 20 BRCA2 mutation carriers with cancer, over a third (7 patients) had multiple cancers. Physicians need to be vigilant to the possibility of synchronous or metachronous development of new cancers in the $B R C A$ mutation carriers, especially those with a $B R C A 2$ mutation. Prostate cancer 


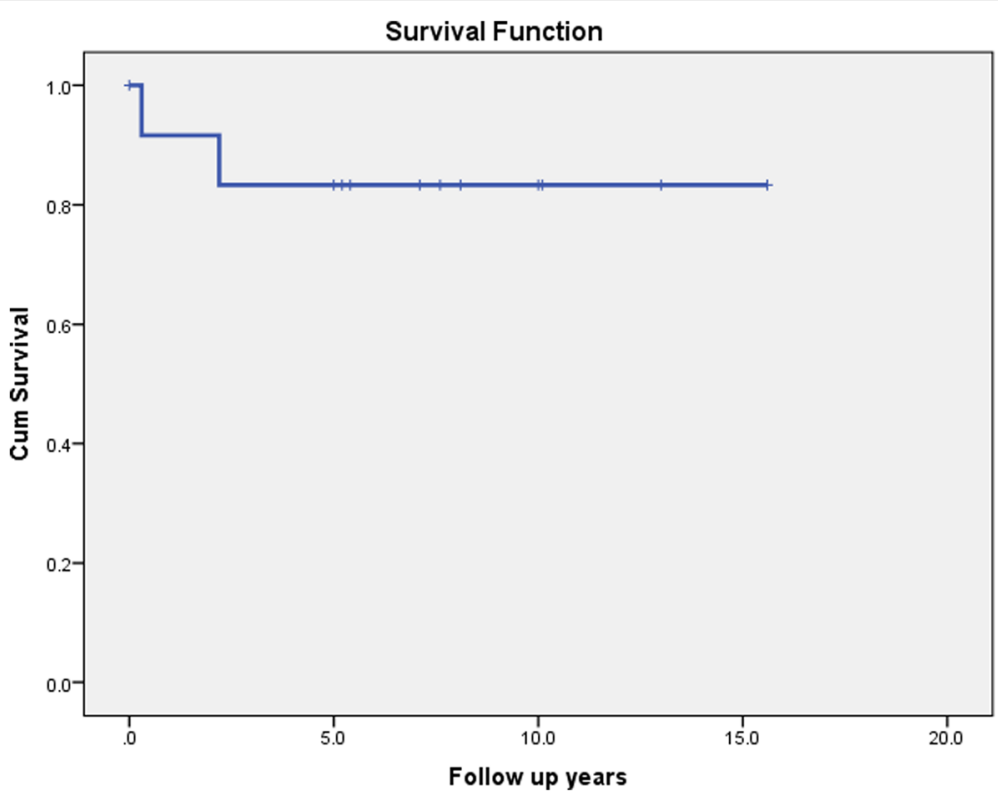

Fig. 3 Kaplan-Meier curve showing overall survival in male BRCA mutation carriers with prostate cancer

was the most common cancer diagnosed in this population followed by male breast cancer, skin cancer, bladder cancer and others.

The majority of cancers were seen in $B R C A 2$ mutation carriers, which is consistent with previously reported data [3-7]. The majority of $B R C A$ associated male breast cancers were high grade, hormone receptor positive and associated with lymph node metastases, which is also consistent with previously reported data [25] It is interesting to note that all of the 7 patients for whom chemotherapy data was available, received chemotherapy. There were no breast cancer related deaths. The impact of chemotherapy on the excellent survival noted in this cohort of patients is intriguing. Homologous recombination repair deficiency seen in BRCA mutated cancers confers higher sensitivity to chemotherapy, especially to DNA damaging agents such as platinum based therapies, due to impaired ability to repair double strand breaks. More than two thirds of patients with breast cancer were alive with no evidence of disease, at a median follow-up of 5.6 years.

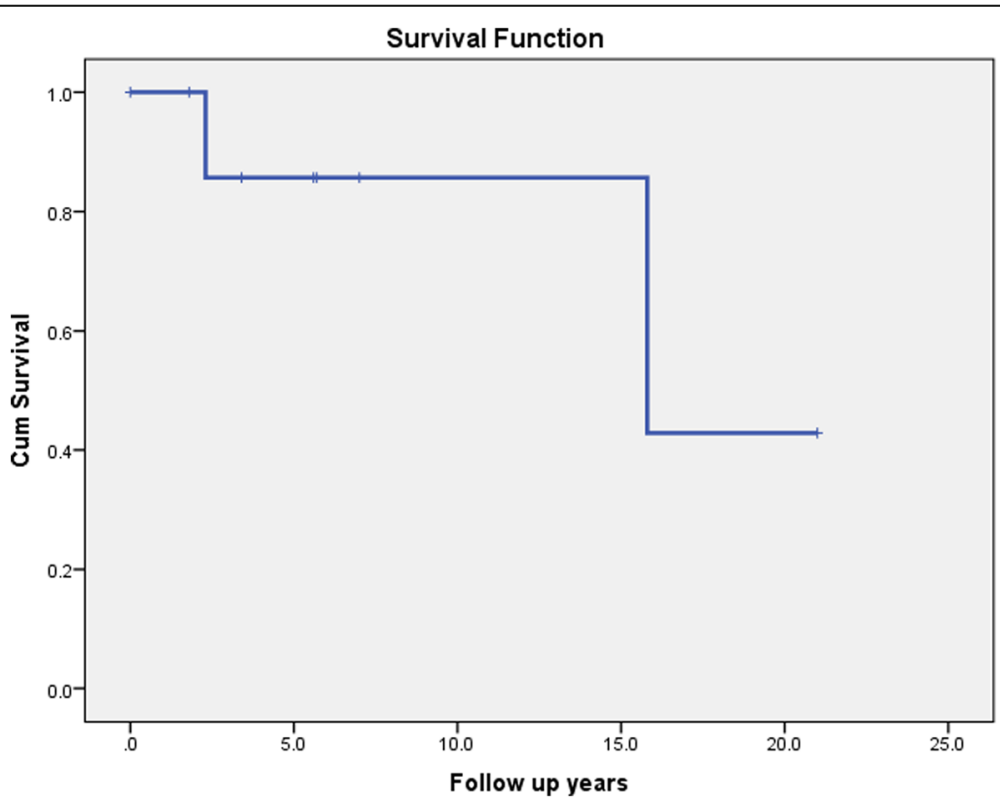

Fig. 4 Kaplan-Meier curve showing overall survival in male BRCA mutation carriers with breast cancer 
Although limited by small size, our study shows that $B R C A$ mutation carriers with prostate cancer had higher Gleason scores, elevated PSA levels and more advanced stage disease, consistent with prior reports [12-14]. The median age of diagnosis with prostate cancer was 68 years, lending support to the recent change in NCCN guidelines to increase the age of prostate cancer screening in BRCA mutation carriers from 40 to 45 years [21].

Of the less common cancers, we observed 1 pancreatic cancer that was interestingly identified in a $B R C A 1 \mathrm{mu}-$ tation carrier. The risk of uveal melanoma (a rare type of melanoma) has been reported to be higher in $B R C A 2$ mutation carriers [7]. We had 3 patients who were diagnosed with melanoma in our study, but neither one of them had an uveal melanoma. One patient had an aggressive stage IV anal melanoma and demonstrated an excellent initial response to a PARP inhibitor on a clinical trial. This observation supports further research into PARP inhibitors in other $B R C A$ related cancers.

Our study had a few limitations, including being a single institution retrospective analysis as well as limited access to treatment records, and somewhat short follow-up.

\section{Conclusions}

This study represents one of the largest studies describing the cancer characteristics of male $B R C A$ mutation carriers. We demonstrated that the majority of cancers seen were breast and prostate with high grade histology and more advanced stages. Favorable impact of systemic chemotherapy may explain the excellent survival in the male breast cancer group. Additional studies are needed with large numbers of patients to better understand the cancer characteristics of male $B R C A$ mutation carriers.

\section{Abbreviations}

AC: Doxorubicin and cyclophosphamide; AC-T: Doxorubicin, cyclophosphamide and paclitaxel; ACTH: Doxorubicin, cyclophosphamide, paclitaxel and trastuzumab; ADT: Androgen deprivation therapy; CMF: Cyclophosphamide, methotrexate and fluorouracil; DCIS: Ductal carcinoma in situ; ER: Estrogen receptor; F/U: Follow-up; FOLFOX: Infusional fluorouracil, leucovorin and oxaliplatin; HER-2: Human epidermal growth factor receptor-2; LN: Lymph node; M: Mastectomy; NED: No evidence of disease; PARP: Poly adenosine diphosphate-ribose polymerase; PSA: Prostate specific antigen; RT: Radiation therapy; TCH: Docetaxel, carboplatin and trastuzumab; TCHP: Docetaxel, carboplatin, trastuzumab and pertuzumab; TURBT: Transurethral resection of bladder tumor

\section{Acknowledgements}

None.

\section{Funding}

None.

\section{Availability of data and materials}

The datasets used and/or analysed during the current study are available from the corresponding author on reasonable request.

\section{Authors' contributions}

Ml designed the study, carried out acquisition, analysis and interpretation of data, drafted the manuscript; SY carried out acquisition, analysis and interpretation of data and critically revised the manuscript, FO carried out acquisition of data and participated in analysis and revised the manuscript; DZ designed the study, participated at interpretation of data and revised the manuscript for intellectual content. All authors read and approved the final manuscript.

\section{Ethics approval and consent to participate}

The requirement for informed consent was waived due to the retrospective nature of the data. This study was approved by the Institutional Review Board at William Beaumont hospital (Ethical approval reference number: HIC 2014-377)

\section{Consent for publication}

Not applicable.

\section{Competing interests}

The authors declare that they have no competing interests.

\section{Publisher's Note}

Springer Nature remains neutral with regard to jurisdictional claims in published maps and institutional affiliations.

\section{Author details}

${ }^{1}$ Department of Hematology/Oncology, Beaumont Health, 3577 W 13 Mile Rd., Ste. 202a, Royal Oak, MI 48073, USA. ${ }^{2}$ Oakland University William Beaumont School of Medicine, 2200 N Squirrel Rd, Rochester, MI 48309, USA. ${ }^{3}$ Hematology-Oncology Fellowship Program, Mayo Clinic, 200 First Street SW, Rochester, MN 55905, USA. ${ }^{4}$ Nancy and James Grosfeld Cancer Genetics Center, Beaumont Health, 3577 W 13 Mile Rd., Ste. 140, Royal Oak, Ml 48073, USA.

Received: 19 June 2017 Accepted: 5 February 2018

Published online: 13 February 2018

\section{References}

1. Easton DF. How many more breast cancer predisposition genes are there? Breast Cancer Res. 1999;1:14-7.

2. Campeau PM, Foulkes WD, Tischkowitz MD. Hereditary breast cancer: new genetic developments, new therapeutic avenues. Hum Genet. 2008;124:31-42.

3. Tai YC, Domchek S, Parmigiani G, Chen S. Breast cancer risk among male BRCA1 and BRCA2 mutation carriers. J Natl Cancer Inst. 2007;99:1811.

4. Evans DG, Susnerwala I, Dawson J, et al. Risk of breast cancer in male BRCA2 carriers. J Med Genet. 2010;47:710.

5. Breast Cancer Linkage Consortium. Cancer risks in BRCA2 mutation carriers. J Natl Cancer Inst. 1999:91:1310.

6. Kote-Jarai Z, Leongamornlert D, Saunders E, et al. BRCA2 is a moderate penetrance gene contributing to young-onset prostate cancer: implications for genetic testing in prostate cancer patients. Br J Cancer. 2011;105:1230.

7. Moran A, O'Hara C, Khan S, et al. Risk of cancer other than breast or ovarian in individuals with BRCA1 and BRCA2 mutations. Familial Cancer. 2012;11:235.

8. Couch FJ, Farid LM, DeShano ML, et al. BRCA2 germline mutations in male breast cancer cases and breast cancer families. Nat Genet. 1996;13:123.

9. Gargiulo P, Pensabene M, Milano M, Arpino G, Giuliano M, et al. Long-term survival and BRCA status in male breast cancer: a retrospective single-center analysis. BMC Cancer. 2016;16:375.

10. Ottini L, Silvestri V, Rizzolo $P$, et al. Clinical and pathologic characteristics of BRCApositive and BRCA-negative male breast cancer patients: results from a collaborative multicenter study in Italy. Breast Cancer Res Treat. 2012;134:411-8.

11. Mitra AV, Bancroft EK, Barbachano Y, et al. Targeted prostate cancer screening in men with mutations in BRCA1 and BRCA2 detects aggressive prostate cancer: preliminary analysis of the results of the IMPACT study. BJU Int. 2011;107:28.

12. Castro E, Goh C, Olmos D, et al. Germline BRCA mutations are associated with higher risk of nodal involvement, distant metastasis, and poor survival outcomes in prostate cancer. J Clin Oncol. 2013;31:1748.

13. Mitra A, Fisher C, Foster CS, et al. Prostate cancer in male BRCA1 and BRCA2 mutation carriers has a more aggressive phenotype. Br J Cancer. 2008;98:502.

14. Thorne H, Willems AJ, Niedermayr E, et al. Decreased prostate cancerspecific survival of men with BRCA2 mutations from multiple breast cancer families. Cancer Prev Res (Phila). 2011;4:1002.

15. Tutt $A$, Ellis $P$, Kilburn $L$, et al. The TNT trial: A randomized phase III trial of carboplatin (C) compared with docetaxel (D) for patients with metastatic or 
recurrent locally advanced triple negative or BRCA1/2 breast cancer. (CRUK 07/012).

16. Tutt A, Robson M, Garber JE, et al. Phase II trial of the oral PARP inhibitor olaparib in BRCA-deficient advanced breast cancer [Abstract]. J Clin Oncol 2009; 27: 15_suppl, CRA501.

17. Tutt A, Robson M, Garber JE, et al. Oral poly(ADP-ribose) polymerase inhibitor olaparib in patients with BRCA1 or BRCA2 mutations and advanced breast cancer: a proof-of-concept trial. Lancet. 2010;376:235.

18. Isakoff SJ, Overmoyer B, Tung NM, et al. A phase II trial of the PARP inhibitor veliparib (ABT888) and temozolomide for metastatic breast cancer [Abstract]. J Clin Oncol 2010; 28:15_suppl, 1019.

19. O'Shaughnessy J, Osborne C, Pippen JE, et al. Iniparib plus chemotherapy in metastatic triple-negative breast cancer. N Engl J Med. 2011;364:205.

20. Mateo J, Carreira S, Sandhu S, et al. DNA-repair defects and Olaparib in metastatic prostate cancer. N Engl J Med. 2015;373:1697-708.

21. National Comprehensive Cancer Network (NCCN) Guidelines for Detection, Prevention, \& Risk Reduction. Genetic/Familial High-riskAssessment: Breast and Ovarian version 2. 2017.https://www.nccn.org/professionals/physician_ $\mathrm{gls} /$ pdf/genetics_screening.pdf. Accessed 30 June 2017.

22. Dudok De Wit AC, Tibben A, Frets PG, et al. Males at-risk for the BRCA1gene, the psychological impact. Psycho-Oncology. 1996;5:251-7.

23. MCAllister MF, Evans DGR, Orminston W, et al. Men in breast cancer families: a preliminary qualitative study of awareness and experience. J Med Genet. 1998:35:739-44.

24. Liede $A$, Metcalfe $K$, Hanna D, et al. Evaluation of the needs of male carriers of mutations in BRCA1 or BRCA2 who have undergone genetic counseling. Am J Hum Genet. 2000;67:1494-504.

25. Silvestri V, Barrowdale D, Mulligan AM, et al. Male breast cancer in BRCA1 and BRCA2 mutation carriers: pathology data from the consortium of investigators of modifiers of BRCA1/2. Breast Cancer Res. 2016;18:15.

\section{Submit your next manuscript to BioMed Central and we will help you at every step:}

- We accept pre-submission inquiries

- Our selector tool helps you to find the most relevant journal

- We provide round the clock customer support

- Convenient online submission

- Thorough peer review

- Inclusion in PubMed and all major indexing services

- Maximum visibility for your research

Submit your manuscript at www.biomedcentral.com/submit

) Biomed Central 